\title{
0 PESQUISADOR COMO 0 OUTRO: UMA LEITURA PÓS-COLONIAL DO "BORAT" BRASILEIRO
}

\author{
THE RESEARCHER AS THE OTHER: A POSTCOLONIAL READING OF THE BRAZILIAN “BORAT"
}

EL INVESTIGADOR COMO EL OTRO: UNA LECTURA POSCOLONIAL DEL "BORAT" BRASILEÑO

\begin{abstract}
RESUMO
Neste artigo, discutimos a aplicação do método etnográfico na pesquisa científica em Administração. Especificamente, ele tem por objetivo analisar como diferenças de cunho colonial preservam hierarquias sociais que acabam se manifestando na prática desse gênero de pesquisa. Resultado de uma etnografia realizada em uma organização britânica, a análise aborda como o pesquisador brasileiro é percebido pelo pesquisado europeu. Para compreender essa relação, utilizamos a abordagem póscolonial e sua crítica ao eurocentrismo e à sua pretensão de alcançar um conhecimento "uni-versal". Os resultados permitem concluir que mesmo na função de pesquisador, o sujeito não europeu, ao tomar o sujeito europeu como o Outro da pesquisa, torna-se alvo de uma inversão que o desloca de volta para a posição do Outro, visto pela epistemologia tradicional como objeto de pesquisa do sujeito europeu.
\end{abstract}

PALAVRAS-CHAVE Pós-colonialismo, pesquisa qualitativa, etnografia, eurocentrismo, América Latina

Rafael Alcadipani rafael.alcadipani@fgv.br

Professor da Escola de Administração de Empresas de São Paulo, Fundação Getulio Vargas - São Paulo - SP, Brasil

Alexandre Reis Rosa areis@espm.br

Professor do Departamento de Organizações e Recursos Humanos, Escola Superior de Propaganda e Marketing - São Paulo - SP, Brasil.

Recebido em 31.07.2009. Aprovado em 15.07.2010

Avaliado pelo sistema double blind review

Editor Científico: Anielson Barbosa da Silva

\begin{abstract}
This paper discusses the application of the ethnographic method in management research. Specifically, it aims to examine how colonial differences preserve social hierarchies that end up being expressed in the practice of scientific research. Using data gathered during an ethnography conducted in a British organization, the analysis addresses how the Brazilian researcher is perceived by Europeans. To analyze this process, we drawn on the postcolonial perspective, especially in its critique of the Eurocentrism and its critique of the desire to develop a "universal" knowledge. The results demonstrate that even in the role of researcher, when the non-European subject takes the European subject as the Other in the research process, he ends up being the target of an inversion that moves him back to the position of the Other, perceived by the traditional epistemology as research object of European subject.

KEYWORDS Postcolonialism, qualitative research, ethnography, eurocentrism, Latin America.

RESUMEN En este artículo discutimos la aplicación del método etnográfico en la investigación científica en Administración. Específicamente, el artículo tiene por objetivo analizar cómo diferencias de carácter colonial preservan jerarquías sociales que acaban manifestándose en la práctica de ese género de investigación. Resultado de una etnografía realizada en una organización británica, el análisis aborda cómo el investigador brasileño es percibido por el investigado europeo. Para comprender esa relación, utilizamos el abordaje poscolonial y su crítica al eurocentrismo y a su pretensión de alcanzar un conocimiento "universal". Los resultados permiten concluir que aun en la función de investigador, el sujeto no europeo, al tomar al sujeto europeo como el Otro de la investigación, se convierte en objeto de una inversión que lo coloca de vuelta en la posición del Otro, visto por la epistemología tradicional como objeto de investigación del sujeto europeo.
\end{abstract}

PALABRAS CLAVE Poscolonialismo, investigación cualitativa, etnografía, eurocentrismo, América Latina. 


\section{INTRODUÇÃo}

Presentemente somos suficientemente livres para constatar que os europeus foram descobertos em Outubro de 1492 pelos indígenas das Caraíbas. Peter Sloterdijk (2008)

Neste artigo, discutimos questões relativas à realização de uma etnografia na condução de pesquisa acadêmica na área de Administração. Trata-se, assim, de uma discussão metodológica relacionada a uma estratégia de pesquisa qualitativa. A reflexão em epígrafe apresenta um deslocamento no significado da chegada dos europeus no continente americano. Ao atribuir a descoberta aos nativos, opera-se uma inversão semântica que explora o ponto de vista dos colonizados ao terem contato com os colonizadores. Isso nos permite pensar de uma forma horizontal em que, ao terem o primeiro contato, duas culturas se descobrem simultaneamente. Logo, cada uma delas teria algo a dizer sobre esse contato, narrando sua própria experiência sobre a descoberta. Contudo, historicamente, não foi assim que as coisas aconteceram e o significado da descoberta ficou nas mãos do colonizador, que monopolizou a narrativa, subordinou a cultura autóctone e impôs sua versão aos outros protagonistas do encontro cultural (SLOTERDIJK, 2008).

Se tomarmos a essência dessa reflexão como um esforço de pensar a descoberta como um evento bilateral, em que ambas as narrativas são legítimas pelo fato de apresentarem visões diferentes do contato cultural, então poderemos dizer que há um esforço de ouvir a voz subalterna e considerar sua narrativa sobre o descobrimento com a mesma validade do colonizador. Atualmente, esse esforço tem sido o núcleo da denominada teoria pós-colonial ou pós-colonialismo, cujo projeto se desenvolve em contexto anglo-saxão a partir dos anos 1980 com essa preocupação de deslocar o olhar para as margens e privilegiar o lugar de enunciação subalterno (ASHCROFT, GRIFFITHS e TIFFIN, 2000).

Um dos principais objetivos do pensamento póscolonial é refletir sobre os efeitos da colonização em culturas e sociedades periféricas. Sendo o continente latino-americano formado por ex-colônias, herdeiro de várias mazelas desse período (e.g., escravidão, exclusão social, dependência econômica e cultural), tais efeitos já foram analisados por outros teóricos brasileiros e latinoamericanos. Como ressalta Mignolo (1996), muito antes dos acadêmicos de língua inglesa, o continente já possuía tradição de estudos nessa linha com os trabalhos de José Carlos Mariátegui, Rodolfo Kush, Leopoldo Zea e Enrique
Dussel (LATIN AMERICAN SUBALTERN STUDIES GROUP, 1993). No Brasil, podemos destacar como exemplo os trabalhos desenvolvidos por Freire (1968), Schwarz (1977) e Santiago (1979).

A questão é que essa tradição latino-americana e principalmente brasileira foi perdendo força diante do processo de modernização do país e da influência cada vez maior dos EUA na região (PEASE, 2005). A redemocratização política seguida da abertura econômica trouxe consigo novas questões de pesquisa, voltou o foco da academia para esses temas e com isso ocultou os efeitos coloniais outrora alvo dos autores citados. Todavia, segundo Souza (2003), no caso brasileiro, sofremos um tipo de "modernização seletiva", uma modernização epidérmica, de fachada, cujos problemas sociais ainda se fazem presentes, ofuscando os efeitos do colonialismo sobre a sociedade brasileira.

Além das consequências políticas, econômicas, sociais e culturais da colonização que ainda persistem no continente latino-americano, há também aquelas epistemológicas, na forma como o "terceiro mundo" é representado no campo científico. O eurocentrismo opera um tipo de "racismo epistêmico" que segrega e dispensa o conhecimento produzido fora de suas fronteiras sob o argumento de ele ser particularístico, incapaz de alcançar a "universalidade" (MIGNOLO, 2006). Romper com essa lógica significa descolonizar o olhar do pesquisador e assumir a produção do conhecimento científico a partir da "pluriversalidade", em que diversas epistemologias são consideradas e potencialmente válidas para compreender o social. Potencialmente porque a descolonização ainda enfrenta o obstáculo das hierarquias coloniais que olham para o Sul como Outro lugar, Outra história, Outra cultura, habitada por Outros sujeitos. Nesse sentido, quando o pesquisador não europeu assume o lugar de sujeito e toma o europeu como o Outro da pesquisa, acaba sendo alvo de uma inversão que o desloca de volta para a posição do Outro histórico, visto pela epistemologia tradicional como objeto de pesquisa, jamais como sujeito.

Considerando o contexto apresentado, nosso objetivo neste artigo é apresentar uma discussão sobre como as diferenças coloniais preservam hierarquias sociais que acabam se manifestando na prática da pesquisa científica. A discussão baseia-se no relato de uma etnografia realizada por um pesquisador latino-americano em uma organização britânica e aborda como esse pesquisador passa pelo processo de Outrificação (torná-lo o Outro) operado pelos pesquisados que, mesmo na condição de Outro, invertem essa lógica com base nas suposições que elaboram acerca do sujeito latino-americano. Para tanto, organizamos o artigo em cinco seções. A primeira apresenta uma breve 
introdução à teoria pós-colonial. Em seguida, apresentamse os desdobramentos dessa teoria nos estudos sobre América Latina. Na terceira seção, descreve-se a metodologia utilizada e nas duas últimas partes relata-se o caso e discutem-se suas implicações na condução de pesquisas qualitativas por pesquisadores brasileiros em países tidos como desenvolvidos a partir da abordagem pós-colonial.

É importante destacar que a discussão presente neste artigo assume um papel preponderante na medida em que a academia nacional pretende, cada vez mais, internacionalizar-se e, para tanto, a condução de pesquisas acadêmicas fora do Brasil é um passo importante. Além disso, o presente debate é relevante dado que anualmente agências de fomento a pesquisa nacional financiam inúmeros estudantes em programas de doutorado sanduíche e também de doutorado pleno, bem como em programas de pós-doutorado realizados em países tidos como de "Primeiro Mundo".

\section{PÓS-COLONIALISMO: ALGUMAS NOÇõES}

Uma das primeiras críticas ao colonialismo surge na reflexão do poeta e político martinicano Aimé Césaire (1971 [1955]) - um dos primeiros intelectuais negros a refletir sobre o sujeito colonial, que, nos anos 1950, juntamente com outras correntes francófonas ligadas a Jean-Paul Sartre (1968 [1956]), analisaram a situação colonial dos países periféricos. O ponto de partida desses precursores era o processo de descolonização, a ruptura com o sistema colonial e com seu discurso universalizante. Ou seja, construir uma narrativa particular como forma de se tornarem sujeito de um destino próprio. Para Césaire (1971), é preciso considerar a "hipocrisia" colonialista que se coloca como evangelizadora, quando na verdade os colonizadores são "piratas", impondo sua lógica ao colonizado. Essas idéias serviram de apoio às de outro influente autor dessa corrente, o também negro e martinicano Frantz Fanon.

Fanon (1963 [1961]; 1967 [1952]) apresenta uma reflexão sobre a alienação sofrida pelos povos colonizados. Em sua primeira análise, Fanon (1967) aborda a questão racial e analisa a colonização como um processo violento que subordina e desumaniza o colonizado, impondo-lhe uma identidade inautêntica. Diante do olhar do Branco, o Negro é visto como coisa, cuja humanidade lhe é negada. Ao interiorizar essa premissa, o colonizado se vê através desse olhar e com isso busca ser reconhecido a partir de uma lógica que é externa ao seu próprio Ser. Para Fanon (1967), a desalienação consiste em superar esse movimento e se libertar dessa ideologia colonial, assumindo sua identidade autêntica, de negro, desalienado do contexto ao qual estava submetido. Em sua segunda análise, influenciada por Césaire e Sartre, Fanon (1963) aborda a questão nacional e defende a violência como saída para a descolonização. Nesse ponto, o autor aborda a questão argelina e assume que a libertação nacional é o único caminho possível para a construção de uma cultura autêntica e nacional.

Em suas análises, Fanon $(1967 ; 1963)$ desenvolve uma proposta de descolonização a partir da busca pela autenticidade com base numa tomada de consciência crítica, seja racial e/ou nacional. Essa proposta nos coloca diante do desafio de pensar a possibilidade histórica de o colonizado assumir um lugar de enunciação privilegiado, formando uma identidade capaz de contrapor o discurso dominante, o discurso colonial. Tal esforço caracteriza a origem da teoria pós-colonial na medida em que será o ponto de partida para que outros autores, também de contextos periféricos, reflitam sobre sua própria condição de colonizado.

$\mathrm{Na}$ esteira desses precursores, agora sob uma perspectiva pós-estruturalista e dentro da démarche pós-colonial, destaca-se o trabalho do palestino Edward Said. Seus trabalhos ganharam projeção no mundo anglófono nos anos 1980 e suas análises se voltaram para o discurso colonial e a sua capacidade de constituir o sujeito colonial. Procuraram avaliar as possibilidades de um contradiscurso equivalente ao esforço de desalienação presente nos trabalhos de Fanon $(1967 ; 1963)$. Ao retomar a crítica ao discurso colonial, Said $(1978 ; 1993)$ traz à tona novas temáticas que estão na órbita desse discurso: orientalismo, imperialismo, nacionalismo, subalternidade, entre outros.

O principal trabalho desenvolvido por Said (1978) é a crítica apresentada no livro Orientalism. Nesse trabalho, o autor critica o Orientalismo como uma visão distorcida do Oriente criada pelo Ocidente para justificar os interesses coloniais na região, definindo os habitantes do mundo oriental como bárbaros. Essa distorção é definida por Said como um "estilo de pensamento", um discurso sobre o Oriente que o ajudou a subordiná-lo e colocá-lo "no seu lugar". Ao analisar esse discurso, Said revela o caráter totalitário e essencialista dessa construção e, sem qualquer pretensão de construir outro discurso sobre o Oriente, apresenta uma nova possibilidade de se estudar a cultura de um povo a partir de uma abordagem não repressiva e não manipuladora (SAID, 1979).

Em outro trabalho, Said (1984) desenvolve essa idéia de constituição do sujeito colonial a partir do discurso dominante presente na pesquisa social. Nesse texto, o 
autor problematiza os estudos elaborados em diversas áreas, tais como antropologia, epistemologia e textualidade, cujas análises raramente abordam as intervenções imperialistas como um fator que afeta as discussões. Ou seja, as representações que são feitas do sujeito colonial nas pesquisas assumem o status científico e acabam narrando esses sujeitos a partir de referências distintas daquelas que eles próprios elaboram sobre sua própria condição. Sendo um sujeito de origem palestina, Said (1984) questiona as inúmeras tentativas de silenciar a voz dos palestinos e o seu esforço de romper com a sua condição de subalternidade que tem prevalecido desde a criação do Estado de Israel (SAID, 1984).

Nesse sentido, Said (1993) aprofunda essa discussão sobre imperialismo, argumentando que o desmantelamento das estruturas coloniais não se resume apenas à desocupação territorial, mas abrangem também idéias, imagens e representações que continuam exercendo influência no mundo periférico. No centro desse argumento, está a ascensão dos EUA após a Segunda Guerra Mundial e sua atual posição de maior potência econômica e militar do mundo contemporâneo (SAID, 1993).

Outro autor importante na démarche pós-colonial, cuja teorização acabou delimitando um subcampo dentro do pós-colonialismo, denominado de subaltern studies, é o indiano Ranajit Guha (1982), que propõe uma releitura da história, considerando o ponto de vista dos subalternos. Seguindo a crítica feita por Said (1978) sobre o Orientalismo, esse autor entende que o subalterno é um produto do discurso dominante, por isso deve-se buscar um modo diferente de ler a história, revelando mitos, cultos, ideologias e revoltas que estão ocultas na versão oficial. Assim, os subaltern studies buscam explorar as fissuras no discurso dominante e introduzir novas vozes, deslocando o lugar de enunciação para as margens (GUHA, 1982).

A proposta indiana dos estudos subalternos acabou influenciando outros grupos a desenvolverem um projeto similar. Com isso, surge o Latin America Subaltern Studies Group (1993), que se apropria do pensamento pós-colonial para analisar o caso especifico da América Latina, conforme discutiremos a seguir.

\section{TROPICALISMO E A CONSTRUÇÃO DO OUTRO}

A América Latina também ocupa espaço na imaginação colonial. A noção de tropicalismo, que é uma forma de Orientalismo (SAID, 1979) aplicada a América Latina, procura evidenciar as representações metropolitanas a respeito dessa parte do mundo e de seus habitantes. Tal região tende a ser construída, desde a sua "descoberta", por meio de escritos de viagem, obras literárias, textos acadêmicos, filmes e pelas diferentes formas de mídia como um subcontinente exótico e luxurioso, um lugar de fauna e flora impressionantes, com clima quente; em suma, quase um paraíso na Terra. Por outro lado, tais características explicariam a letargia e o atraso da região. Tal atraso, ainda segundo essas diferentes produções, também seria dado por características inerentes aos nativos, geralmente tidos como corruptos, indolentes, exóticos, inferiores e extremamente emocionais. Assim, os "tristes trópicos" , outrora analisados por Lévi-Strauss (1981), seriam um local de decadência e prazeres e habitado por um povo inferior (APARICIO e CHAVEZ-SILVERMAN,1997).

$\mathrm{Na}$ verdade, diferentes formas de produção de conhecimento e cultura Européia e Anglo-Saxã construíram os demais povos e suas civilizações como objetos de análise desprovidos de história e características próprias, auxiliando na construção do Outro subdesenvolvido do Ocidente desenvolvido. O Tropicalismo e o Orientalismo são claros exemplos disso. Tal fato ainda pode ser evidenciado, por exemplo, na origem da etnografia, já que os primeiros trabalhos desse tipo eram realizados por europeus que tinham por objetivo visitar e desvendar as particularidades de sociedades não européias. Ainda hoje, muitos estudos desse tipo focam sociedades tidas como "primitivas". Os etnógrafos invariavelmente comparavam, mesmo que de forma sutil, as sociedades analisadas com as suas próprias, tratando os povos do Novo Mundo e da África como primitivos, inferiores, bestiais e menos desenvolvidos. Tais relatos foram de grande importância para os gestores metropolitanos caracterizarem os nativos e assim poder dominá-los de forma mais efetiva (PRASAD, 1997). Outro exemplo é dado por expressões literárias européias. Mignolo (2005) discute o lado obscuro do Renascimento. Ao analisar diferentes formas literárias, cartografias e historiografias, o autor destaca o papel exercido pela linguagem na colonização do Novo Mundo. Especificamente, ele afirma que formas renascentistas de expressão literária e cartográficas desempenharam papel importante na colonização das Américas ao auxiliarem na construção de uma imagem que denegria esse lugar nas metrópoles do Velho Mundo. A questão torna-se mais grave quando o "primitivo" passa a aceitar a descrição colonial como verdadeira e a se considerar inferior.

Dentro desse contexto, a noção de América Latina é bastante problemática. No início do processo de colonização da América, o continente era considerado (na verdade, foi construído como) inferior, apesar da com- 
plexidade de várias civilizações lá presentes antes de seu "descobrimento". Tal idéia do continente como inferior à Europa durou até meados de 1898, quando ocorreu a guerra Espanha-Estados Unidos (MIGNOLO, 2008). É importante destacar que a divisão do mundo em diferentes regiões e continentes é fruto de uma distribuição de poderes das potências coloniais Européias. Com o passar do tempo e o advento das guerras pela independência, começa a emergir a idéia de América Latina como algo inferior e dependente dos Estados Unidos, opondo-se, assim, à noção de uma América que não é latina e que se define em oposição a ela. Além disso, tal noção trata como semelhante uma parte do continente repleta de diversas tradições culturais, complexidades e heterogeneidades. $\mathrm{O}$ mesmo ocorre dentro dos Estados Unidos, onde o termo latino americano acaba por simplificar e homogeneizar mais de 40 milhões de pessoas provenientes da região que habitam aquele país (MIGNOLO, 2008).

Na verdade, com a ascensão e consolidação dos Estados Unidos como potência econômica e militar, aprofundouse o processo de a idéia de América Latina servir como personificação de uma oposição para a autoimagem estadunidense (MIGNOLO, 2008). Ao fazer uma análise da construção histórica do conceito "Latin America" nas ciências sociais, principalmente estadunidenses, Feres Jr. (2004) argumenta que existem oposições assimétricas em termos de semântica do conceito. A definição da América Latina aparece como negação ou ausência dos hábitos, costumes e instituições dos Estados Unidos. Por meio dessa oposição, a "América" se reafirma como protestante, universalista e democrática, ao passo que a sua versão latina seria católica, particularista e autoritária. Além disso, a "América" se define como branca e anglo-saxã enquanto sua versão latina é representada pelo não-branco e mestiço. Dessa forma, a "América" surge como desenvolvida e o seu oposto, a "Latina", seria subdesenvolvida e atrasada. Ou seja, a "Latin America" se reforça como oposição negativa de uma imagem autoglorificada dos Estados Unidos (FERES JR., 2004). Há nisso consequências práticas, já que tal definição acabou por influenciar as intervenções militares dos Estados Unidos na região.

Do centro dessa idéia de América Latina emerge o sujeito latino-americano, como a corporificação dela. Fruto do encontro colonial, denominado de descoberta, o sujeito latino-americano representa o significado construído em torno das diferenças fenotípicas entre o sujeito europeu e o sujeito autóctone. Para Quijano (2000), foi a partir dessas diferenças que se produziram identidades sociais capazes de classificar quem era o dominante e quem era o dominado. Ao se produzir tipologias como "índio", "ne- gro", "mestiço", se produzem também, por contraste, as figuras do "espanhol", "português", "britânico", que em um segundo momento passam a se agrupar nas figuras de "Latino" e de "europeu", que até então indicava a localização geográfica desses sujeitos. Contudo, os desdobramentos históricos da "descoberta" fizeram tais diferenças assumirem uma conotação racial, estabelecendo hierarquias, lugares e papéis sociais correspondentes a elas.

Por muito tempo, essas hierarquias estiveram invisíveis na produção do conhecimento científico, supostamente visto como "neutro". O ego cogito cartesiano ("penso, logo existo") criou o dualismo sujeito-objeto, colocando o primeiro como possuidor de uma verdade "universal" a respeito do segundo. Assim, a filosofia ocidental assume o papel de sujeito possuidor de uma consciência universal (leia-se ocidental eurocêntrica) fundamentada na idéia de pensamento científico. Como desdobramento disso, Dussel (1994) argumenta que, antes mesmo de Descartes criar o ego cogito, a expansão colonial européia, deflagrada a partir de 1492, havia criado o ego conquistus ("conquisto, logo existo"). Ou seja, a arrogância do pensamento científico ocidental de se colocar no lugar de Deus, como sujeito possuidor de uma verdade universal, foi precedida pelas condições históricas, políticas, econômicas e sociais geradas pela colonização do mundo não ocidental. O fundamento imperial formado nesse período moldou a subjetividade daqueles que estavam no centro de um mundo que eles "descobriram" e organizaram (ou pelo menos tentaram) à sua própria imagem.

Conforme já discutimos, essa suposta universalidade vem sendo problematizada pela teoria pós-colonial. $\mathrm{Na}$ perspectiva subalterna, todo conhecimento produzido é sempre situado, pois falamos sempre de algum lugar nas relações de poder, uma vez que ocupamos ao mesmo tempo um lugar epistêmico e um lugar social que se traduz numa geopolítica do conhecimento (MIGNOLO, 2002). Assim, a filosofia ocidental também fala de algum lugar e esse lugar geopolítico foi denominado por Grosfogel (2006) de "sistema-mundo europeu/euro-norteamericano moderno/capitalista/colonial/patriarcal", cuja premissa básica é a da "egopolítica do conhecimento" em detrimento da "geopolítica do conhecimento". Ou seja, na perspectiva ocidental eurocêntrica, prevalece o "ego" não situado, escondido atrás da enunciação sem nome e sem rosto. Ao desvincular o "lugar epistêmico" do "lugar social", a figura do sujeito universal fica preservada, garantindo assim sua suposta "neutralidade".

Quando a crítica pós-colonial reconhece a existência desses dois lugares e da sua dupla existência na produção do conhecimento, rompe com a dicotomia sujeito-objeto e 
coloca em xeque a legitimidade do sujeito universal como portador de uma verdade sobre o Outro, sobre as minorias discriminadas outrora vistas como "objeto" de etnografias "neutras", sem nome e sem rosto (egopolítica do conhecimento). Ao romper essa linha, o antigo objeto se coloca como sujeito e começa a produzir conhecimento sobre si mesmo e também sobre o antigo sujeito universal, agora visto como possibilidade de ser o Outro da pesquisa. No entanto, conforme será discutido no relato a seguir, essas rupturas e possibilidades de se produzir conhecimento sobre Outro se tornam pouco nítidas na prática cotidiana da pesquisa. Pois nesse espaço específico de relações algumas hierarquias tradicionais continuam operando a partir de diferenças de cunho colonial, impedindo que o sujeito subalterno se situe como sujeito e de que o objeto seja tomado como o Outro.

\section{METODOLOGIA}

Os dados para este artigo foram coletados durante uma etnografia conduzida por um dos autores deste artigo em uma das maiores gráficas de jornal da Europa localizada do Reino Unido. É importante frisar que o objetivo original dessa etnografia era analisar práticas de organizar na produção de jornais, mas que, como tende a ocorrer em pesquisas desse tipo, muitas outras coisas surgiram durante o processo de investigação (HAMMERSLEY e ATKINSON, 1995).

Na gráfica de jornais, de agora em diante denominada como Press para preservar o anonimato da empresa e de seus funcionários, são impressos semanalmente inúmeros periódicos, incluindo diários de expressiva circulação nacional naquele país. São impressos tanto "tablóides" quanto jornais considerados localmente como de "qualidade". A gráfica produz mais de 15 milhões de exemplares de diários a cada semana. Localizada no norte da Inglaterra, nela estão nove rotativas operadas praticamente 24 horas por dia. Quando a pesquisa aconteceu, na Press havia 290 empregados, dentre os quais 106 trabalhavam exclusivamente nas máquinas impressoras de jornal, o principal foco do estudo de campo. A imensa maioria das pessoas que trabalhavam na fábrica era composta de homens, ingleses e brancos, cujas idades variavam entre 40 e 59 anos. Na realidade, havia apenas três funcionários que fugiam a essa regra: um gerente e um operário, ambos de origem indiana, e uma gerente mulher e anglo-saxã de Recursos Humanos. Vale frisar que a Press faz parte de um dos maiores grupos de mídia no mundo. Somente no Reino Unido, ele possui mais de 500 diferentes marcas de produtos relacionados à informação, mais de duas centenas de jornais locais e regionais, cinco jornais de circulação nacional e emprega mais de 10.000 pessoas com um faturamento anual de cerca de $\mathrm{R} \$ 3,4$ bilhões.

Não obstante as dificuldades associadas com qualquer definição geral do que seja etnografia, dada a sua diversidade e complexidade, é possível argumentar que ela geralmente envolve "o etnógrafo participando aberta ou de maneira escondida, na atividade de um dado grupo por um período de tempo estendido, observando o que acontece, escutando o que é dito, fazendo perguntas - de fato, coletando todo o tipo de dado disponível para iluminar assuntos e eventos que estão no foco de sua pesquisa" (HAMMERSLEY e ATKINSON, 1995, p. 1). Nesse sentido, um prolongado contato com o campo é uma de suas características fundamentais (AGAR, 1980). Na verdade, trata-se de um método em que o pesquisador sai da Torre de Marfim acadêmica para viver com aqueles que são estudados, sendo que a única forma de se tornar um etnógrafo é ir a campo e realizar um estudo (VAN MAANEN, 2006). Dessa forma, a etnografia deriva da experiência em "primeira mão" do pesquisador no local pesquisado e está comprometida em compreender o ponto de vista daqueles que são pesquisados. Esse método tem sido fundamental para desenvolver uma compreensão aprofundada do mundo da administração, das organizações e do trabalho. Para Van Maanen (1979, p. 540), etnografias organizacionais tendem a "revelar e explicitar formas e maneiras como as pessoas que trabalham em locais particulares vem a entender, explicar, tomar atitudes e gerir suas situações cotidianas".

Os dados que serviram de base para este artigo foram coletados de meados de Setembro de 2005 até o final de Junho de 2006. Durante esse período, um dos autores acompanhou as atividades cotidianas na Press. Ele foi à empresa durante todas as semanas desses meses, tipicamente 5 dias por semana, permanecendo de 8 a 12 horas por dia. Após o término de cada dia de observação, o pesquisador redigiu diários de campo, de acordo com a prática do campo (SANJECK, 1990), em que relatava os principais eventos observados na organização. No total, foram produzidas pouco mais de 2.000 páginas de diários de campo. O pesquisador codificou os dados por meio da leitura exaustiva dos diários, a fim de encontrar temas e temáticas, tanto teóricas quanto empíricas, recorrentes. Para tanto, utilizou-se do software Atlas Ti, mas não recorreu a nenhum dos recursos de codificação eletrônica, tendo, portanto, todo o controle do processo de codificação. Além disso, o pesquisador tirou mais de 2.500 fotografias, coletou cerca de 1 GB de documentos 
e um total de 63 desenhos realizados por funcionários da fábrica de jornais.

Logo no primeiro encontro com pessoas que podiam liberar o acesso na organização para que a etnografia fosse realizada, a questão da nacionalidade brasileira do pesquisador gerou reações e comentários. Tais reações continuaram a acontecer praticamente até o último dia da pesquisa de campo. Como parecia algo que poderia gerar discussões interessantes, o pesquisador procurou anotar exaustivamente minúcias de tais eventos, muitos dos quais serão detalhados a seguir. Vale destacar que existem diferentes possibilidades para se realizar uma narrativa etnográfica e aqui se optou por uma descrição confessional, cuja característica fundamental é o uso da primeira pessoa, pois se entende que a narrativa possui um autor que ocupa um lugar geopolítico, ou seja, epistêmica e socialmente situado.

\section{PESQUISADOR COMO OUTRO: BRASILEIROS "BORAT"}

Após alguns minutos aguardando na recepção, sou chamado para iniciar a reunião agendada com o editor de um dos principais jornais regionais da Inglaterra. Eu havia, por intermédio de um conhecido em comum, conseguido agendar, finalmente, um encontro para discutir a possibilidade de eu realizar uma pesquisa etnográfica no jornal que ele comandava. Entro na sala decorada como um escritório qualquer, com certo ar de modernidade. Sentado está um homem aparentando 45 anos, que logo vem até a porta me receber. Vestido com um terno bem cortado, aperta a minha mão de forma firme e efusiva. Quando começo a falar e antes mesmo de sentar, sou interrompido com a pergunta: "Mas de onde você é?" Ao responder que sou brasileiro, ele abre um sorriso e começa a falar de futebol. Eram alguns meses antes da Copa do Mundo da Alemanha e o sorridente editor queria saber como eu via as chances do Brasil na competição. Conversamos cerca de 10 minutos a respeito de futebol, jogadores brasileiros, jogadores ingleses e as previsões para a Copa. O clima fica amistoso, cordial. O gelo parece quebrado e, a partir daí, começamos a falar a respeito da pesquisa.

O mesmo aconteceu quando eu me encontrei com o CEO do jornal, pessoa com quem eu também deveria falar para conseguir acesso para a pesquisa. No nosso encontro, na maior parte do tempo, falamos a respeito de futebol, já que ele conhecia alguns times e jogadores brasileiros. Falamos, ainda, das diferenças entre os estilos brasileiro e britânico de se jogar. A conversa evoluiu ao ponto de que, no final da nossa reunião, ele pediu para que a secretária trouxesse dois convites para o camarote de um jogo de futebol da Primeira Liga inglesa que aconteceria no final de semana. O jornal possuía um camarote no estádio. Eu fiquei bastante satisfeito e surpreso com isso. A reação de falar a respeito de futebol ou automobilismo, principalmente de Ayrton Senna, foi extremamente comum com os meus interlocutores durante a pesquisa de campo, assim que eles sabiam de onde era meu estranho sotaque e, consequentemente, minha nacionalidade. Tais conversas serviam, em larga medida, para amenizar o encontro e eu acredito que gerava certa empatia por mim.

Outra reação comum, ao descobrirem onde eu havia nascido e vivido grande parte de minha vida, era de surpresa. Muitos pareciam não acreditar que alguém do Brasil mudara para a Inglaterra, na verdade, para o Norte daquele país, lugar onde o clima e o tempo não são exatamente agradáveis. "Nossa! Do Brasil? É mesmo? Como você aguenta o clima deste lugar?" Reações desse tipo eram corriqueiras. Na realidade, eu sentia que para eles o Brasil era um lugar muito distante não apenas em termos físicos, mas também culturais. Perguntas a respeito de quantas vezes por semana eu dançava, de como é o carnaval, das praias brasileiras, sempre tomadas como paradisíacas, eram insistentemente frequentes. Na verdade, o script era primeiro falar de futebol e/ou Fórmula 1 (geralmente com homens) e depois a respeito do clima e lugares paradisíacos do Brasil. No geral, havia uma idéia de que brasileiros são um povo amigável, feliz e que aprecia as boas coisas da vida. Eu sentia nas conversas que tinha com os ingleses que vários deles gostariam de morar em um lugar com o clima e as belezas naturais de nosso país e que, também, tivesse um povo com a nossa alegria.

Em poucas ocasiões, houve casos de comentários que eu achava pouco adequados para serem feitos de forma direta logo nos primeiros contatos. Por exemplo, uma vez, fui conhecer uma gráfica de jornais e o diretor da gráfica começou a comentar que, no passado, na Inglaterra, as pessoas tinham que ligar para uma central telefônica onde havia telefonistas que ficavam diante de painéis com vários buracos e cabos onde elas conectavam a ligação manualmente. Ao dizer isso, virou-se para mim e disse: "Ah! Você sabe, né? Lá no Brasil é ainda assim", denotando claramente a visão de que o Brasil seria uma país bastante subdesenvolvido. Em outra ocasião, fui recebido por um diretor financeiro do grupo proprietário da Press. Essa reunião foi algumas semanas após a execução do brasileiro Jean Charles de Menezes no metrô londrino pela polícia daquele país. Assim que o diretor descobriu que eu era brasileiro, ele disparou veementemente: "Como o 
governo do seu país ousa questionar as ações da polícia britânica que acabaram por terminar com a vida desse imigrante ilegal? No seu país, a polícia se diverte matando as pessoas e nada acontece. Este senhor era um imigrante ilegal, assim como existem milhares no sul de Londres. Estas pessoas vêm para cá, não tem o direito de viver no meu país e quando algo assim acontece é culpa de nosso governo? O que o seu governo faz para proteger as pessoas do seu país da polícia? O que ele faz para impedir que essas pessoas que passam fome venham para cá? Antes de vir pedir por justiça aqui, eles deveriam fazer com que haja justiça no seu país." Fiquei bastante incomodado com os comentários e não podia reagir de forma muito incisiva, pois temia que o diretor pudesse terminar o meu acesso de pesquisa. Apenas disse que eu não era um representante oficial do governo brasileiro e sugeri que ele escrevesse para a Embaixada do Brasil para manifestar sua opinião. A fala do diretor denota a idéia de que o Brasil é uma terra bárbara e sem lei. Outro evento digno de nota foi quando me apresentei para um operário que, ao saber que eu era brasileiro, disse: "Somente um fodido do terceiro mundo se interessaria em pesquisar a gente", indicando que a própria autoimagem do operário não era das melhores.

Porém, estas foram exceções de comentários mais incisivos a respeito do Brasil que aconteceram de forma direta na minha primeira interação com pessoas. O que tendeu a ocorrer foi que, apesar do tom ameno das primeiras perguntas e comentários geralmente ligados a futebol, automobilismo e belezas naturais, conforme destacado acima, quando a relação se tornava um pouco mais próxima, as perguntas e comentários mais constrangedores começavam a surgir. Por exemplo, um tema muito recorrente na interação com os operários do chão de fábrica dizia respeito às mulheres brasileiras. Inúmeras vezes, durante o estudo de campo, operários perguntavam com curiosidade extrema se as brasileiras usavam pouca roupa no cotidiano, se os seus corpos eram realmente perfeitos como aparecia nas revistas e jornais, principalmente se elas tinham de fato nádegas avantajadas e como era a experiência de fazer sexo com uma brasileira. Muitos relatavam conhecer amigos que vieram ao Brasil para ter sexo fácil em festas regadas a drogas e bebidas. Outros, majoritariamente homens acima de 40 anos, diziam que tinham amigos que visitaram o Brasil e conseguiram facilmente mulheres para se casar, pois, segundo seus relatos, brasileiras adorariam mudar para a Europa para poder ter uma casa com máquina de lavar, lava-louças etc. Chegavam a indagar se qualquer mulher de nosso país mudaria para o Reino Unido em troca de uma casa com eletricidade e a possibilidade de assistir televisão, além de desfrutar diariamente de um prato de comida. A imagem da mulher brasileira para meus interlocutores parecia ser de pessoas com sexualidade libertina, além de serem extremamente subdesenvolvidas.

Quando as primeiras perguntas ocorreram, eu levava na brincadeira e de certa forma confirmava os estereótipos com uma boa dose de humor. Na medida em que percebi que os comentários eram extremamente frequentes, comecei a ficar incomodado. Por exemplo, comecei a responder que no Brasil as mulheres usavam, sim, menos roupa nas cidades de praia, onde há Sol e calor, mas que achava inusitado o fato de que inglesas usavam roupas diminutas para sair à noite em uma temperatura que beirava zero grau. Em outra ocasião, discuti o fato de ter visto pessoas em danceterias no Reino Unido praticando sexo no banheiro, algo que jamais havia visto acontecer no Brasil Diante de questionamentos a respeito de mulheres brasileiras que queriam mudar para o exterior, discuti com o meu interlocutor o fato de muitos europeus virem para o Brasil em busca de "escravas" para levar para a Europa e também para praticar pedofilia. Sei que estas foram reações bastante emocionais, mas eu as via como uma forma de relativizar a visão pejorativa da mulher brasileira.

Em termos de sexualidade, havia comentários a respeito da presença de travestis no Brasil. Alguns acreditavam que no Brasil a bissexualidade e o transformismo eram práticas corriqueiras. Por exemplo, uma noite, quando eu acompanhava uma equipe de técnicos de manutenção, o supervisor de manutenção me chamou para conversar na sala dele. Após alguns rodeios, ele me perguntou se havia muitos travestis no Brasil. Um tanto quando constrangido, respondi que nosso país possui centenas de milhares de pessoas e que há de tudo. Repentinamente, ele começou a dizer que eu ficaria muito bem usando salto alto, um vestido longo e maquiagem. Pensei que se tratava de uma brincadeira, mas o inglês, que tinha cerca de 50 anos, persistiu nos comentários e me convidou para ir jantar com ele no final de semana. Respondi, de forma bastante agressiva, que esta não era minha opção sexual e ele disse diretamente que acreditava que no Brasil a bissexualidade e o transformismo fossem práticas corriqueiras entre os homens. Ao perceber minha indignação, pediu para que eu não comentasse o ocorrido com seus colegas, pois eles não sabiam que ele era dado a esse tipo de prática.

Havia, ainda, uma idéia de que o Brasil era extremamente subdesenvolvido. Em algumas ocasiões, fui questionado se as casas no Brasil eram feitas de tijolos e telhas. Em outras, se havia coisas como internet banda larga disponível por aqui. Houve, ainda, questionamentos a respeito da higiene dos brasileiros. Em uma ocasião, 
após uma sala de reuniões ter sido invadida por um mau cheiro, um gerente, em tom de piada, perguntou se eu havia produzido flatulências. Disse, em tom jocoso: "E aí Brasileiro, foi você quem peidou?" Fiquei muito constrangido e sem reação. Percebendo a indelicadeza, ele logo se desculpou. Em outra ocasião, houve uma virose estomacal que se espalhou pela empresa. Ao perceber que eu não havia sido contaminado, um gerente me disse: "Você não pegou o vírus, né? É que você vem do Brasil e seu organismo está acostumado com esses vírus, não é verdade?" Nesse dia, não respondi nada, mas fiquei extremamente indignado pelo fato de eu achar que a higiene da cozinha da empresa ser muito abaixo daquela que eu estava acostumado no Brasil.

Nossas mazelas sociais também foram assunto de questionamento. Diversas vezes, fui questionado se eu estava acostumado a correr da polícia quando era pequeno, se já havia passado fome e se meu pai era traficante. Havia aqueles que questionavam a respeito do desmatamento da Amazônia e defendiam que o governo brasileiro não era capaz de defender esse patrimônio. Muitos falavam da corrupção do governo e das questões sociais mais amplas. Como se tratava de uma gráfica de jornais, várias vezes vi notícias bastante negativas serem impressas a respeito do Brasil, geralmente relacionadas com o tráfico de drogas, problemas ambientais e questões alimentares. Todas as vezes que essas matérias eram impressas, algum impressor vinha me mostrar o que estava sendo dito e qual era a minha opinião. Em geral, concordava que essas coisas existem e tentava relativizar. Sentia-me, porém bastante constrangido nessas situações.

Houve uma situação ainda inusitada durante a pesquisa de campo. Na fábrica de jornais, os operários tinham o costume de colocar nas paredes fotos para fazer piadas com colegas de trabalho ou com situações que eles estavam vivenciando. Um dia, pouco depois de quinto mês que eu estava no campo, ao chegar ao chão de fábrica, um dos funcionários disse; "Cara, vai lá no mural ver a foto que colocaram de você. Você tá lindo!". Ao ir até o mural da rotativa, deparei-me com uma imagem. Havia cerca de 30 cópias dessa imagem espalhadas por diferentes pontos do chão de fábrica.

Trata-se do personagem "Borat", da comédia que leva o mesmo nome. Na comédia, ele é um estrangeiro que viaja pelos Estados Unidos fazendo diversos absurdos, figurando a imagem de um não Ocidental que comete as maiores gafes possíveis. É um homem primitivo, ignorante e que não parece conhecer os modos e hábitos "civilizados". Na foto postada nos murais e em algumas paredes, foi colocada uma seta, apontando ambiguamente ou para os genitais da figura ou para o maiô do personagem, e foi escrito que eu estava "exibindo meu brasileiro", não ficando claro se seria o maiô ou o órgão genital. Embora eu tenha entendido o tom de brincadeira dessa ação, chamou-me a atenção de terem escolhido justamente o Borat para me representar. Além disso, escolheram justamente uma foto em que ele aparece em trajes sumários. Indaguei-me se essa foto teria sido escolhida e se essa frase teria sido escrita se eu não fosse brasileiro. Ou seja, acredito que a brincadeira só teve o tom de humor por comparar-me ao Borat, ou melhor, por me fazer semelhante a ele e também mostrar os trajes sumários e a sexualidade geralmente atribuída aos brasileiros. Após ouvir todos os comentários acima, comecei a me questionar se essa foto não representaria justamente como eles percebem os brasileiros ou se seria um espelho deles mesmos e de suas próprias idiossincrasias. Ou as duas coisas, talvez.

\section{DISCUSSÃO}

Ao analisar o relato acima à luz da discussão teórica apresentada, observamos diversos momentos em que a descrição se sobrepõe aos conceitos discutidos. No primeiro contato do pesquisador com os pesquisados, ocorre o evento que pode ser considerado o ponto de partida de todas as análises subsequentes. A pergunta: "Mas de onde você é?" delimita o lugar social que o pesquisador ocupa e é a partir desse lugar que ele será visto por todos os pesquisados com os quais ele interage durante a pesquisa. Contudo, ao se demarcar o lugar do pesquisador, como um latino-americano, por contraste o lugar de quem pergunta também é demarcado.

$\mathrm{Na}$ perspectiva da geopolítica do conhecimento, esse lugar também é epistêmico e, tratando-se do sujeito europeu, podemos dizer que esse lugar é do "sistema-mundo europeu/euro-norte-americano moderno/capitalista/colonial/patriarcal", discutido por Grosfogel (2006). Não apenas por se tratar de um europeu, senão estaríamos usando o lugar social como sinônimo de lugar epistêmico, mas, sobretudo, pelas enunciações sobre o Outro, que o relato apresenta. Quando os pesquisados assumem esse lugar geopolítico de enunciação, iniciam o processo de Outrificação do sujeito latino-americano (que agora é objeto), deixando emergir em suas falas cada um dos itens que compõem seu lugar de enunciação. Por essa razão, os primeiros diálogos são amistosos. Afinal, qual o lugar do futebol nas relações centro-periferia? Por outro lado, este é um forte marcador da imagem do Brasil no exterior, reduzindo seu papel no mundo ao de "terra do futebol". 
Somente quando os diálogos adentram outras temáticas é que a geopolítica do conhecimento se manifesta e faz surgir um tipo de Tropicalismo que serve de pano de fundo para as enunciações e reproduz o mesmo efeito discursivo do Orientalismo criticado por Said (1979).

A primeira manifestação disso surge nos comentários sobre o brasileiro Jean Charles. Nesse relato, a imagem primitiva de um Brasil colonial reconhecido (ou construído) pelos colonizadores como sendo uma terra "Sem Fé, Sem Lei, Sem Rei". Essa tríade era a principal justificativa para a catequização forçada dos índios, para o transplante do aparato jurídico português e para a presença de uma nobreza que pudessem "civilizar" o povo primitivo da região. Nesse sentido, como poderia esse povo questionar o governo britânico? Com isso, cria-se uma justificativa para as atrocidades contra estrangeiros ou supostos "terroristas", conforme se alegou no caso Jean. Aliás, esta foi também a justificativa dos EUA para a invasão do Iraque e a morte de vários civis inocentes. Como mostra Said (1979), o Oriente ocupa o imaginário do Ocidente como uma terra primitiva, habitada por bárbaros e pela banalização da violência. Tal qual o executivo britânico se referia ao Brasil.

Nos comentários sobre sexualidade, a visão patriarcal fica bastante clara ao colocarem a mulher como mero objeto de prazer e luxúria. A banalização do corpo feminino, como sensual e rotineiramente sem roupas, nos remete aos relatos de viagem do período colonial em que o continente era descrito como um tipo de Éden onde as mulheres nuas eram amantes insaciáveis, afeitas às vontades da carne sem nenhum pudor. Quando eles se referem à possibilidade de elas se mudarem para o Reino Unido em troca de uma vida confortável com eletricidade, TV, máquina de lavar e refeições diárias, fica evidente a dimensão europeu/moderno/capitalista que associa a idéia de "desenvolvimento" à posse de bens de consumo e ao usufruto de um estilo de vida moderno. Esse subdesenvolvimento do "terceiro mundo" também fica evidente no relato das centrais telefônicas.

Entre todos os episódios presentes no relato, o mais significativo para nossa análise é a fotografia do personagem Borat distribuída em diversos pontos da fábrica, pois essa imagem, além de materializar todo o conjunto de suposições que eles formularam sobre o sujeito latino, também se apresenta como ponto nodal que articula os diversos lugares ocupados tanto pelo sujeito latino como pelo sujeito europeu.

Quando olhamos a fotografia apenas pelo seu significado superficial de imagem em si, observamos o Tropicalismo em todas as suas formas. Desde a praia ao fundo - que sugere os locais paradisíacos imaginados pelos britânicos - passando pelo traje de banho exótico - que sugere uma forma típica de vestimenta, um tanto erótica e afeminada - até a genitália em destaque - que sugere a lascívia e o orgulho de exibi-la sem pudores - a figura de Borat é o ponto de chegada do processo de Outrificação do pesquisador, que agora possui uma identidade Borat atribuída pelos sujeitos europeus. Contudo, se descentrarmos o Borat e olharmos o que está por detrás do personagem da foto, outras possibilidades de interpretação dessa suposta identidade latino-americana aparecem, aproximando-se e ao mesmo tempo afastando-se do seu lugar social de origem.

O contexto original do personagem no filme sugere duas interpretações possíveis de acordo com o contexto desse artigo. O primeiro é o de que Borat é um jornalista estrangeiro que viaja entrevistando pessoas vinculadas a grupos que vão desde sulistas norte-americanos, passando pelas feministas, até uma elite próxima à realeza britânica. Nessas entrevistas, Borat se destaca por expor de forma sutil preconceitos terríveis que são revelados pelos entrevistados em meio ao humor e a palhaçadas que os deixam à vontade para expor seu lado mais obscuro, sem que percebam suas exteriorizações. Nessa primeira interpretação, o Borat se aproxima do pesquisador latinoamericano, mas dessa vez não de forma pejorativa. Na verdade, há um significativo paralelo aos relatos vividos pelo pesquisador durante sua pesquisa, pois os interlocutores também expuseram seus preconceitos em meio ao humor.

A segunda interpretação possível afasta Borat do pesquisador latino e aproxima-o dos próprios europeus que refletem nele suas próprias idiossincrasias. No filme, o personagem Borat se destaca também pelos diversos comentários ofensivos que faz, com declarações machistas, homofóbicas, de ódio contra judeus e até apologias à pedofilia e ao incesto. No entanto, apesar da agressividade dos comentários, Borat não formula suas opiniões de maneira organizada a partir de uma intolerância com motivações pessoais. Suas opiniões reproduzem a socialização que o personagem teve na fictícia vila de Kuzcek, no Cazaquistão, onde conviveu com situações diversas como a de ficar viúvo, de mesmo jovem já possuir netos, de ter uma irmã prostituta e um irmão com problemas mentais. Tais situações levam Borat a desenvolver uma interpretação bastante particular da realidade, chegando ao ponto de admirar o ditador Josef Stalin por causa do seu pênis e a apoiar George W. Bush na sua luta contra o terror. Isso tudo mesmo depois de ser considerado um dos melhores repórteres de sua terra natal. Ou seja, nessa segunda interpretação de Borat, temos uma figura 
que expressa diversos preconceitos que estão vinculados ao lugar geopolítico que ele ocupa. Dessa forma, não se trata de um processo elaborado de forma consciente; na verdade, são visões hegemônicas que habitam o imaginário do personagem e o fazem externalizá-las nas mais inusitadas situações.

A reação dos ingleses perante um pesquisador latinoamericano apresentada na sessão anterior mostra, essencialmente, o imaginário tropicalista em ação como um vetor importante durante o processo de pesquisa etnográfica organizacional que envolve pessoas de um país central e um país periférico. O interessante, aqui, é também perceber que o latino-americano, mesmo sendo o etnógrafo, torna-se objeto desse processo. Parece indicar a tentativa de estabelecer o pesquisador, principalmente devido a sua nacionalidade, como o Outro daquela sociedade e daquele lugar. Trata-se de um Outro que representa uma sociedade subalterna que é inferiorizada e vista como primitiva (GUHA, 1982). Opera-se, assim, uma construção do sujeito da pesquisa como objeto de diversos preconceitos. Por outro lado, a análise também nos ajuda a categorizar o sujeito Anglo-Saxão como possuidor de uma mentalidade colonial remanescente. Com isso, considerando o argumento de Said (1984) sobre a constituição do sujeito na pesquisa social, os elementos aqui discutidos podem ser um passo importante para um processo mais amplo de descolonização da pesquisa etnográfica oriunda de países periféricos que se confrontam com países centrais.

\section{CONSIDERAÇÕES FINAIS}

Nosso objetivo neste artigo foi discutir como as diferenças coloniais preservam hierarquias sociais que se manifestam na prática da pesquisa científica em administração. Para tanto, apresentamos noções gerais sobre a teoria pós-colonial, discutindo principalmente os trabalhos de Said sobre o Orientalismo e de Guha sobre o sujeito subalterno. Em seguida, abordamos a diferença colonial discutida por esses autores, que gerou reflexões similares no continente latino-americano. Entre essas reflexões, surge o conceito de "geopolítica do conhecimento", que traduz a sobreposição entre o lugar social e o lugar epistêmico do sujeito que fala, pois visa a romper com a visão "egopolítica" calcada em uma perspectiva cartesiana que insiste em produzir o sujeito universal que não fala de lugar algum.

Ao problematizar essa visão, a teoria pós-colonial nos permite enxergar questões outrora invisíveis, como, por exemplo, as hierarquias coloniais que operam no momen- to da pesquisa. Tais hierarquias tendem a não reconhecer o sujeito subalterno como tal, deslocando-o para a sua posição tradicional de objeto do sujeito europeu. Contudo, ao analisar a experiência de pesquisa de um dos autores, esse deslocamento produz múltiplas possibilidades de construção do Outro da pesquisa.

O caso específico do brasileiro "Borat", construído pelo sujeito europeu a partir de uma imagem tropicalizada desse personagem cinematográfico, nos remete a mais de uma possibilidade de construção. Na verdade, ao olharmos para as múltiplas identidades que o Borat pode assumir, observamos um sujeito fragmentado que se desloca entre os lugares sociais e os lugares epistêmicos. Assim, quando os operários fixaram as fotos do Borat por toda a fábrica, estavam conscientemente tentando representar o lugar social do pesquisador latino-americano - exótico, sensual, bissexual etc., mas, inconscientemente, acabaram representando a si próprios e ao lugar epistêmico que ocupam - no "sistema-mundo europeu/euro-norte-americano moderno...". Essa dupla possibilidade a partir do descentramento do Borat conecta os dois lugares de onde o sujeito fala (social e epistêmico) e nos remete ao caráter híbrido da geopolítica do conhecimento, que desconstrói a dicotomia sujeito-objeto, mostrando-nos as dificuldades de operá-la na prática da pesquisa.

Sendo assim, concluímos com essa análise que o recurso metodológico de se construir o Outro da pesquisa com vistas a gerar o chamado estranhamento, que muitas vezes nos leva a investigar esse Outro como "coisa", é empiricamente impossível de ser operado quando lidamos com hierarquias sociais que atribuem dado valor às diferenças coloniais. Nesse sentido, esperamos que essa reflexão contribua para outra, mais ampla, acerca dos limites e possibilidades da pesquisa etnográfica em organizações nacionais e/ou transnacionais, cada vez mais habitadas por Outras culturas, Outras histórias, Outros costumes vindos de muitos Outros lugares.

\section{REFERÊNCIAS}

AGAR, M. The professional stranger: an informal introduction to ethnography. New York: Academic Press, 1980.

APARICIO, F; CHÁVEZ-SILVERMAN. F. Tropicalizations: Transcultural Representations of Latinidad. Dartmouth: University of New England Press, 1997.

ASHCROFT, B.; GRIFFITHS, G.; TIFFIN, H. The Post-Colonial Studies: The key concepts. London: Routledge, 2000 
CESAIRE, A. Discurso sobre o colonialismo. Porto: Poveira, 1971 [1955].

DUSSEL, E. 1492: el encubrimiento del Otro: hacia el origem del mito de la modernidad. La Paz: Plural Editors, 1994.

FANON, F. Black skin, white masks. New York: Grove Press, 1967 [1952].

FANON, F. The wretched of the earth. New York: Grove Press, 1963 [1961].

FERES JR. J. Latin America como Conceito: a constituição de um outro americano. Teoria e Sociedade, v.11, n. 2, p.18-41, 2004.

FREIRE, P. Pedagogia do oprimido. Rio de Janeiro: Paz e Terra, 1968.

GROSFOGUEL, R. La descolonización de la economía-política y los estudios poscoloniales: transmodernidad, pensamiento fronterizo y colonialidad global. Tabula Rasa, n. 4, p. 17-48, 2006.

GUHA, R. Subaltern studies. Oxford: Oxford University Press, 1982.

HAMMERSLEY, M.; ATKINSON, P. Ethnography: principles in practice. London; New York: Routledge, 1995.

LATIN AMERICAN SUBALTERN STUDIES GROUP. Founding Statement. Boundary 2, v. 20, n. 3, p. 110-121, 1993.

LÉVI-STRAUSS, C. Tristes trópicos. São Paulo: Martins Fontes, 1981.

MIGNOLO, W. Herencias coloniales y teorías postcoloniales. In: STEPHAN, B. (Org) Cultura y Tercer Mundo. Caracas: Editorial Nueva Sociedad, 1996.

MIGNOLO, W. Os esplendores e as misérias da "ciência": colonialidade, geopolítica do conhecimento e pluriversalidade epistêmica. In: SOUSA SANTOS, B. (Org) Conhecimento prudente para uma vida decente: um discurso sobre as ciências revisitado. 2. ed. São Paulo: Cortez, 2006.

MIGNOLO, W. The darker side of the Renaissance. Chicago: University of Michigan Press, 2005.

MIGNOLO, W. The geopolitics of knowledge and the colonial difference. The South Atlantic Quarterly, v.101, n. 1, p. 57-96, 2002.

MIGNOLO, W. The idea of Latin America. London: Blackwell, 2008.
PEASE, D. US Imperialism: global dominance without colonies. In: SCHWARZ, H.; RAY, S. (Eds) A Companion to Postcolonial Studies. Oxford: Blackwell Publishing, 2005.

PRASAD, A. The colonizing Consciousness and representations of the other In: PRASAD, P.; MILLS, A.; ELMES, M. (Eds) Managing the Organizational Melting Pot. London: Sage, 1997.

QUIJANO, A. Coloniality of power, ethnocentrism, and Latin America. Nepantla, v. 1, n. 3, p. 553-580, 2000

SAID, E. Culture and imperialism. New York: Vintage, 1993.

SAID, E. Orientalism. New York: Viking, 1978.

SAID, E. Representing the colonized: anthropology's interlocutors. Critical Inquiry, v. 15, p. 205-225, 1989

SANJEK, R. Fieldnotes: the makings of anthropology. Ithaca: Cornell University Press, 1990

SANTIAGO, S. Uma literatura nos trópicos: ensaio sobre dependência cultural. São Paulo: Perspectiva, 1979.

SARTRE, J. P. Colonialismo e neocolonialismo. Rio de Janeiro: Tempo Brasileiro, 1968 [1956].

SCHWARZ, R. As idéias fora do lugar. In: Ao vencedor as batatas: forma literária e processo social nos inícios do romance brasileiro. São Paulo: Duas Cidades, 1977.

SLOTERDIJK, P. Palácio de cristal: para uma teoria filosófica da globalização. Lisboa: Relógio D’Água, 2008.

SOUZA, J. A construção social da subcidadania: para uma sociologia política da modernidade periférica. Belo Horizonte: UFMG, 2003.

VAN MAANEN, J. The fact and fiction in organizational ethnography. Administrative Science Quarterly, v. 24, n. 4, p. 539-550, 1979.

VAN MAANEN, J. Ethnography then and now. Qualitative Research in Organizations and Management, v. 1, n. 1, p. 13-21, 2006. 